\title{
STUDY ON THE IMPORTANCE OF PHYSICAL EXERCISE IN THE RECOVERY AND SOCIAL INTEGRATION OF PUPILS WITH SPE- CIAL NEEDS
}

\author{
Pehoiu $\mathrm{C}^{1}$, Pehoiu Andra ${ }^{2}$, Savu $\mathrm{C}^{3}{ }^{\circledR}$ and Cristea $\mathrm{D}^{4}$ (1) \\ ${ }^{1}$ Department of Physical Education and Sport, Faculty of Humanities, Valahia University of Targoviste, Romania \\ ${ }^{2}$ Member of the Centre for the Study of Environment, Habitat and Leisure Activities - Faculty of Humanities, Faculty of \\ Humanities, Valahia University of Targoviste, Romania \\ ${ }^{3}$ Department of Physical Education and Sport, Faculty of Humanities, Valahia University of Targoviste, Romania \\ ${ }^{4}$ Department of Physical Education and Sport, Faculty of Humanities, Valahia University of Targoviste, Romania
}

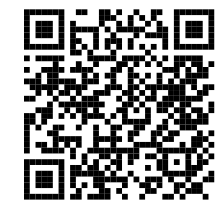

Received 3 April 2021

Accepted 18 April 2021

Published 30 April 2021

\section{Corresponding Author}

Pehoiu C, Pehoiu Andra, cpehoiu@ yahoo.com, andra $\neg$ pehoiu@yaho o.com

DOI $10.29121 /$

granthaalayah.v9.i4.2021.3808

Funding: This research received no specific grant from any funding agency in the public, commercial, or not-for-profit sectors.

Copyright: (C) 2021 The Author(s). This is an open access article distributed under the terms of the Creative Commons Attribution License, which permits unrestricted use, distribution, and reproduction in any medium, provided the original author and source are credited.

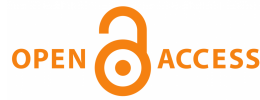

\section{ABSTRACT}

Children in the category of people with special needs must, because they have the right, benefit from an educational approach that ensures their development and recovery, on the one hand, and, on the other hand, social integration or reintegration under non-discriminatory conditions regarding capabilities, skills, abilities or personality.

The study aims to integrate knowledge, methods, forms and means specific to the field of motion science into activities that are meant to optimize health status, growth and physical development and the possibilities for their recovery and social integration of the children with special needs

The study took place in the on a group of 10 students and 26 teachers and physiotherapists. Methods that are part of the category of those specific to the educational field were used, namely: scientific documentation, observation, pedagogical experiment, opinion questionnaire, statistical-mathematical processing, graphic representation.

Considering the heterogeneity of the subjects, following the application of the physical exercise program and the tests of evaluation of the motricity, an appreciable progress is observed in 8 of them, which represents $80 \%$; for the remaining $20 \%$, the progress made does not change the status of people with a low level of motor ability, namely speed, strength and endurance.

Keywords: Skills, Effort, Exercise, Recovery, Integration, Equality

\section{INTRODUCTION}

Children with special needs depending on their typology, the cultural environment, the family in which they live, are often faced with the decision to be excluded from the 
program of a normal life, which leads, to varying degrees, to the manifestation of anxiety, to less pleasant affective-emotional feelings and experiences both at their level and at that of the people in the immediate proximity Abid and Aslam (2013). Scientific and social experience data attest that the optimal integration in a determined social environment is not based solely on intellectual faculties and on the accumulation of moral, scientific, aesthetic values, s.a.m.d., but necessarily also on the development of the body resulting in a healthy, fortified, harmoniously structure organism, able to cope with social exigencies. Integration through physical development has multiple implications for the intellectual side, for the development of individuality as a spiritual being. Research in the field of psychology has shown that, in various situations, human consciousness is also related to the development of the body, to its concrete reality "Autism Speaks - Servicii Pentru Familie. Ghidul Comunității Şcolare" (2013); C. Pehoiu et al. (2017). Thus, it can be considered that physical activities of children with special needs, performed during schooling, ensure their social recovery and integration. In general, movement determines the state of health whose maintenance or improvement require activities in the motor category beyond those considered mandatory and every day, practising physical exercise in various forms being the cheapest therapy in the recovery of posture attitudes and against the appearance and disease setting.

The need for special protection in the case of children with special needs is often known in terms of the syntagms used, such as sick children who are difficult to recover, handicapped children and physically and mentally retarded children, this endeavour being a minor contribution to improve the life that this category of fellow human beings live, and a way to identify the hardships they face in everyday life "Autism Speaks - Servicii Pentru Familie. Ghidul Comunității Şcolare" (2013); Gherguț et al. (2009); Gherguț (2006); Verza and Specială (1993); Vrăşmaş et al. (1998); Vrăşmas (2000). In this context, socio-human sciences (medicine, economics, politics, pedagogy, sociology, etc.) insist with more and more consistency on practising physical exercise as an efficient, educational prophylactic means, ultimately as a means of integration and a specific manner of society to fight the effects caused by it Dumitru (1997); Ilinca (2010); Marcu (1995); Pehoiu et al. (2004). From this point of view, the specific physical education and sport functions - the harmonious physical development of the human body and the social integration and improvement of the way of expressing the motor capacity of the human individual - reveal the compensatory value of the exercise in relation to the modern life. The use of exercise is a way to counteract the disintegration action of social domains and activities, a reaction to nervous wear and tear towards mental and physical fatigue caused by contemporary society. The biomedical perspective of practicing physical exercises highlights their therapeutic role but especially that of preventing the occurrence and installation of diseases. The role of physical education and sports activities in public health can be appreciable if we start from the fact that movement has a major influence on growth and physical and mental development, 
on the improvement of the functional capacity and on the effort adjustment of the human body Clerget et al. (2008); Florea (2008); Moisin (2007); Momanu et al. (2009); Nicola and Pedagogie (1996). At the same time, physical exercise, especially when used in an analytical form, actively influences the prevention, diminishing or correction of bodily attitudes or physical deficiencies which are not in accordance with the normality of the period of growth and development Hollowood et al. (1994); Staub (2005). Maintaining a high degree of optimal and efficient functioning, of adjustment to physical and mental effort, regardless of life span, gender, and characteristics or requirements of social activities, ensures biological balance, social adaptation and integration Debesse et al. (1970); Epuran and Fizice (1978); Golu et al. (1994); Jinga et al. (2001); Pehoiu et al. (2004); Popescu-Neveanu and Psihologie (1978). The movement is the one that can prove the existence of the psychic life with which it is until the appearance of the language. The expressive dimension of human movement is manifested in bodily postures, gestures and facial expressions, thus resulting in nonverbal or paraverbal aspects of communication. So, the movement is socialized, and through it it becomes meaningful for the one who realizes it, as well as for the one who looks at it Epuran and Stănescu (2010); Wallon et al. (1978). At the same time, the movement is favorable for maintaining the integrity of the body, its absence or limitation for long periods of time can trigger pathological conditions that can affect the functionality and body consciousness Epuran and Stănescu (2010); Mellier and Mouvment (1993).

The study aims to integrate knowledge, methods, forms and means specific to the field of motion science into activities that are meant to optimize health status, growth and physical development of children / pupils with special needs, to build self-confidence, responsibility, courage, to develop interpersonal relationships, group cohesion, the possibilities for their recovery and social integration.

The following hypotheses were formulated to achieve this goal:

1. We believe that the attributes / qualities that need to be developed in the process of recovery and social integration of pupils with special needs C. Pehoiu et al. (2017), as well as their importance within this process, can be determined by a sociological opinion survey including specialists working at this educational level;

2. We believe that by applying specific means of physical education represented by dynamic games with a theme, relay races and applicative paths, exercises aimed at developing motor skills, we will contribute to an improvement in the general motricity of children with special needs;

3. Applying physical exercise programmes that include, in particular, dynamic games with a theme, relay races and applicative paths will lead to the improvement of interpersonal relationships, group cohesion and the diversification of possibilities for social recovery and social integration of children with special needs C. Pehoiu et al. (2017). 


\section{MATERIALS AND METHODS}

The criteria underlying the selection of subjects, in fact, of a class of students have been: the deficiencies they suffer from should be of medium level and as close as possible in terms of the way of manifestation and the level of good physical education achieved by the class teacher, during the previous school year. The present study has focused on were 10 male students, aged 15-16 years, attending a special school in the urban area (Table 1 ). At the same time, 26 teachers and physiotherapists, involved in the research, answered a questionnaire in which they expressed their opinions about the importance of physical exercise on the cognitive, affective, volitional and psychomotor development of children with special problems.

Table 1 Data on subjects included in the study

\begin{tabular}{ccc}
\hline Subjects & Age & Type of deficiency \\
1 & 15 years & Medium-hyperkinetic mental deficiency \\
2 & 16 years & Minor mental deficiency, behavioral disordes \\
3 & 16 years & Minor mental deficiency \\
4 & 16 years & Minor mental deficiency, language disordes \\
5 & 15 years & Minor mental deficiency, behavioral disordes \\
6 & 15 years & Minor mental deficiency, language disordes \\
7 & 16 years & Minor mental deficiency - hyperkinesia \\
8 & 16 years & Medium mental deficiency \\
9 & 16 years & Medium mental deficiency muscular atony, language \\
& & disordes \\
10 & 16 years & Minor mental deficiency, behavioral disordes \\
\hline
\end{tabular}

The research methods used for the study are part of the category of general or particular methods specific to the educational field, namely: the bibliographic research method, observation, the pedagogical experiment method, the sociological survey method based on the application of the questionnaires, the method of statisticalmathematical processing, the method of graphic representation. The sociological survey method used to obtain and interpret data/information/options from certain individuals about a particular phenomenon in our case has been employed to:

1. gathers opinions on the importance of intellectual/cognitive C. Pehoiu et al. (2017), psychomotor, affective, volitional qualities in increasing the level of expressing motor skills, in the recovery and social integration of pupils with special needs. In order to obtain the data, a questionnaire of 5 questions was applied to a number of 26 teachers and physical therapists, the content of which aimed to rate (1-5 points) an inventory of the abovementioned qualities Jinga et al. (2001); Karstina and G (2021). The task of the subjects was to rank the qualities according to the following answer options: very important 5 points; important - 4 points; relatively important - 3 points; less important 2 points; very little important - 1 point. 
2. records the opinions of the 10 subjects, pupils with special needs, on the improvement of interpersonal relationships, of the group cohesion coefficient as a result of practising organized physical exercise. To obtain the structural elements of the socio-metric test, subjects were asked before and after the completion of the study, to answer a socio-metric questionnaire consisting of 4 questions. Based on the obtained answers, the socio-metric matrix was created (a double entry table), where each subject is inscribed on the basis of a predefined code (in our case from Y1 to Y10) and which expresses the centralized results of the number of all preferences, and of rejections from the questionnaire response, respectively; based on the results, the socio-metric status (Iss) and the preferential status (Isp), corresponding to each subject, are calculated using the following formulas: Iss = no. of the choices received $/ \mathrm{n}-1$; Isp = no. of elections - no. of rejections / n-1. After calculating the socio-metric and preferential status indices, we have calculated the group cohesion coefficient (Cgr) according to the formula: Cgr $=\Sigma$ preferences - Erejections $/$ Epreferences + इrejections. The results obtained have been compared with those in (Table 2 ).

Table 2 Values on the interpretation of group cohesion indices Matei (1981)

\begin{tabular}{ccc}
\hline No & Values & The degree of cohesion \\
\hline 1. & From -1 to -0.70 & $\begin{array}{c}\text { Dissociated group } \\
\text { Explosive (tense) group }-0.69 \text { to }-0.40\end{array}$ \\
\hline 3 & From- 0.39 to -0.20 & $\begin{array}{c}\text { Group with dissensions } \\
\text { Group at the beginning of the } \\
\text { disorganization }\end{array}$ \\
\hline 5 & From- 0.19 to- 0.01 & Group of contradictory forces \\
\hline 6. & 0 & Group with low cohesion \\
\hline 7. & From 0.01 to 0.20 & Group with small cohesion \\
\hline 8. & From 0.21 to 0.40 & Moderate (medium) cohesion group \\
9. & From 0.41 to 0.60 & Group with significant cohesion \\
10. & From la 0.61 to 0.80 & Group with great cohesion \\
\hline
\end{tabular}

The research protocol aimed at implementing in the specialized lessons, at the level of the group formed by the 10 student subjects (independent variable), a program of physical exercises (dependent variable), with the following content: relay races (2) and applicative pathways (2); dynamic theme games - included in four packages, each of which responds to a specific purpose; namely sociability (5); finding solutions (3); communicating for success (2); taking responsibility, developing courage, initiative, etc. (2); specific exercises aimed at developing motor skills, as well as components of general motor ability. The program was applied during the 2016-2017 school year, with the approval of the management of the special school and the support of the specialist teacher from this educational institution, as well as the written consent of the parents of the 10 subjects. Also, all the regulations in force 
regarding the research ethics were taken into account and observed, thus ensuring the physical, mental and social safety of the subjects.

Subjects were tested twice in 6 motricity tests in September 2016 and the end of May 2017. The tests used (25-meter speed running, standing long jump, $600 \mathrm{~m}$ resistance running, two hand overhead throw with medicine ball, fixed barpull-ups, trunk lift from the prone position for $30 \mathrm{sec}$ - Table 3 ), aimed at assessing the level of manifestation of motor capacity and were considered accessible in terms of the way of application to the subjects included in the present study.

\begin{tabular}{|c|c|c|c|c|c|c|c|c|c|c|}
\hline Motricity tests/points & $\begin{array}{c}10 \\
\mathbf{p}\end{array}$ & $\begin{array}{c}20 \\
\mathbf{p}\end{array}$ & $\begin{array}{c}30 \\
\mathbf{p}\end{array}$ & $\begin{array}{c}40 \\
\mathbf{p}\end{array}$ & $\begin{array}{c}\mathbf{5 0} \\
\mathbf{p}\end{array}$ & $\begin{array}{c}60 \\
p\end{array}$ & $\begin{array}{c}70 \\
p\end{array}$ & $\begin{array}{c}\mathbf{8 0} \\
\mathbf{p}\end{array}$ & $\begin{array}{c}90 \\
\mathbf{p}\end{array}$ & $\begin{array}{c}100 \\
p\end{array}$ \\
\hline Speed running 25 m-seconds (sec) & 6.8 & 6.6 & 6.4 & 6.2 & 6 & 5.8 & 5.6 & 5.4 & 5.2 & 5 \\
\hline $\begin{array}{l}\text { Standing long jump -centimeters } \\
(\mathrm{cm})\end{array}$ & 70 & 80 & 90 & 100 & 110 & 120 & 130 & 140 & 150 & 160 \\
\hline $600 \mathrm{~m}$ resistance - minutes (min) & 3.30 & 3.20 & 3.10 & 3 & 2.50 & 2.40 & 2.30 & 2.20 & 2.10 & 2 \\
\hline $\begin{array}{l}\text { Overhead throw with medicine } \\
\text { ball - } 3 \mathrm{~kg} \text { - metra (m) }\end{array}$ & 3.2 & 3.4 & 3.6 & 3.8 & 4 & 4.2 & 4.4 & 4.6 & 4.8 & 5 \\
\hline Pull-up - repeat (rep) & 1 & 2 & 3 & 4 & 5 & 6 & 7 & 8 & 9 & 10 \\
\hline Trunk lift - repeat (rep) & 11 & 12 & 13 & 14 & 15 & 16 & 17 & 18 & 19 & 20 \\
\hline
\end{tabular}

\section{RESULTS AND DISCUSSIONS}

We have used a direct research questionnaire with a view to collecting subjective data, opinions on the main psychomotor, intellectual, affective, volitional and dimensional qualities of personality necessary for social recovery and social integration through the activity of physical education and physical therapy. That being the objective, we have applied the questionnaire to a number of 26 physical education and physical therapy teachers working in institutions for pupils with special needs, and school units where there are pupils with special needs integrated by special groups and classes. $70 \%$ of respondents surveyed believe that motor perceptual skills and basic motor skills (93.3\%) are the most important aspects of the psychomotor dimension required for the recovery and social integration of children with special educational needs. The questioned teachers considered that motor intelligence $(76.6 \%)$ and concentration $(66.6 \%)$ are the most important dimensions in the intellectual-cognitive sphere of young people with special needs. Resistance to stress (86.6\%) and affective balance (83.3\%) are the two defining aspects in the recovery and integration of pupils with special needs. The volitive component of students was $83.3 \%$ for discipline and self-control, $80 \%$ for ambition, laziness, perseverance and $76 \%$ for volunteer effort. The surveyed subjects scored $93.3 \%$ for interest and motivation of the students for the chosen profession and $80 \%$ for the correct attitudes towards the peers. 
Compared with the initially recorded results, in the final test we find an improvement in the mode of manifestation of the motor capacity of all subjects, although this is not spectacular, but we consider it worthwhile considering the status of those who were part of the present study.

Thus, in the 25-metre speed test, dedicated to speed capacity assessment, at the end of the research, we notice an improvement of $0.1-0.2 \mathrm{sec}$. of the times recorded for 7 subjects out of 10, and for two of them a performance stagnation (subjects 2 and 5, $4.6 \mathrm{sec}$ and $5.2 \mathrm{sec}$ respectively in both tests), results that led to maintaining the initial score (90-100 points),for a number of 6 , an improvement by 5-10 points for subjects 4, 6, 9 and 10 (Figure 1 ).

The average performance value is $5.02 \mathrm{sec}(0.02 \mathrm{sec}$ over the scale of the rating scale corresponding to 100 points). Although subject no. 9 has improved his performance, he remains in the lowest performance area.

25 meters speed test

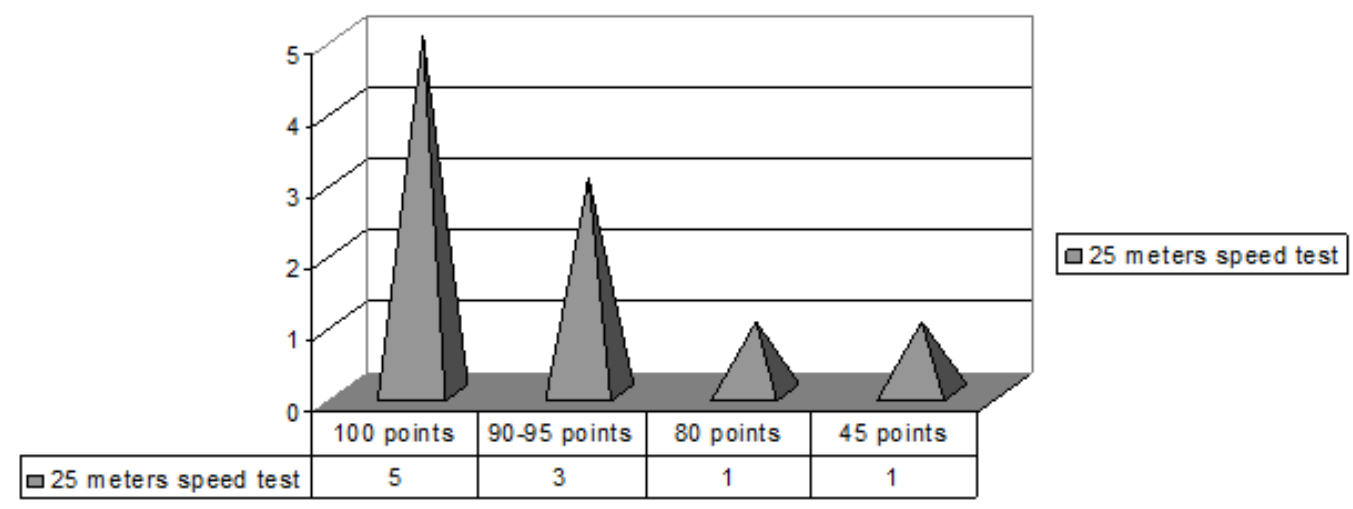

Figure 1 Assign the number of points obtained atthe 25 meters speed test

The data presented in Table 4 highlights that, in terms of expressing the strength of lower limbs (explosive force), if initially only 4 subjects had superior indices, which represented $40 \%$ of their total, in the end the number of those who achieved the maximum score increased to 5, i.e. 50\%; 4 achieved performances that brought them a score between 80 and 95 ; one alone achieved 50 points with a 15 point progress from the original one, the subject no. 9 (S.A., from $95 \mathrm{~cm}$ to $110 \mathrm{~cm}$ ). The performances of all subjects improved by $1-10 \mathrm{~cm}$, the mean value of the first 5 was $166 \mathrm{~cm}, 6 \mathrm{~cm}$ above the value in the evaluation scale.

Table 4 Performances and scores recorded by subjects in the initial and final testing in the standing long jump

Subjects
Initial
Points
Final 


\begin{tabular}{ccccc}
\hline Table 4 continued & \multicolumn{3}{c}{} \\
\hline 1 & $155 \mathrm{~cm}$. & 95 points & $163 \mathrm{~cm}$. & 100 points \\
2 & $162 \mathrm{~cm}$. & 100 points & $161 \mathrm{~cm}$. & 100 points \\
3 & $161 \mathrm{~cm}$. & 100 points & $162 \mathrm{~cm}$. & 100 points \\
4 & $151 \mathrm{~cm}$. & 90 points & $155 \mathrm{~cm}$. & 95 points \\
5 & $141 \mathrm{~cm}$. & 81 points & $146 \mathrm{~cm}$. & 86 points \\
6 & $140 \mathrm{~cm}$. & 80 points & $145 \mathrm{~cm}$. & 85 points \\
7 & $172 \mathrm{~cm}$. & 100 points & $175 \mathrm{~cm}$. & 100 points \\
8 & $169 \mathrm{~cm}$. & 100 points & $169 \mathrm{~cm}$. & 100 points \\
9 & $95 \mathrm{~cm}$. & 35 points & $110 \mathrm{~cm}$. & 50 points \\
10 & $135 \mathrm{~cm}$. & 75 points & $140 \mathrm{~cm}$. & 80 points \\
\hline
\end{tabular}

Although it does not seem a significant increase, however, these results represent the influence of the exercise programme proposed by us on the 10 subjects, especially if we take into account that the progress of motricity in the case of people with special needs is slow, corresponding to a long period of activity.

The final results in the 600 meters resistance test (Table 5 ) demonstrate, as in previous studies, that 9 subjects improved their performance in terms of general resistance capacity, the progress being between 1-10 seconds; only one maintained his result, namely subject no.9, who ran the 600-metre distance in 2.25 minutes in both tests.

\begin{tabular}{|c|c|c|c|c|}
\hline Subjects & Initial & Points & Final & Points \\
\hline 1 & $1.54 \mathrm{~min}$. & 100 points & $1.50 \mathrm{~min}$. & 100 points \\
\hline 2 & $1.50 \mathrm{~min}$. & 100 points & $1.51 \mathrm{~min}$. & 100 points \\
\hline 3 & $1.50 \mathrm{~min}$. & 100 points & 149 min. & 100 points \\
\hline 4 & $2.09 \mathrm{~min}$ & 90 points & $2.05 \mathrm{~min}$ & 90 points \\
\hline 5 & $2.10 \mathrm{~min}$. & 90 points & $2.05 \mathrm{~min}$ & 90 points \\
\hline 6 & $2.25 \mathrm{~min}$ & 75 points & $2.25 \mathrm{~min}$ & 75 points \\
\hline 7 & $1.40 \mathrm{~min}$. & 100 points & $1.35 \mathrm{~min}$. & 100 points \\
\hline 8 & $1.56 \mathrm{~min}$. & 100 points & $1.52 \mathrm{~min}$. & 100 points \\
\hline 9 & $3.10 \mathrm{~min}$. & 30 points & $3.05 \mathrm{~min}$. & 35 points \\
\hline 10 & $2.30 \mathrm{~min}$. & 70 points & $2.20 \mathrm{~min}$. & 80 points \\
\hline
\end{tabular}

Compared to the initial results, the final ones recorded at the two-hand overhead throw with the $3 \mathrm{~kg}$ medicine ball are, most of them (90\%), close to the maximum score that could be achieved. Thus, only 5 subjects scored results that brought them the maximum score of 100 points. Three of these performances corresponded to the score of $80-90$ points and the remaining 2 , meaning $20 \%$ of the total score, scored between 50 and 60 points. The final average value of the performances is 4.88 meters (12 cm below the score scale corresponding to 100 points) compared to 4.64 meters originally recorded, the difference being 24 centimetres ( 0.24 metres), which we consider to be an appreciable progress. 
Fixed bar pull-ub test

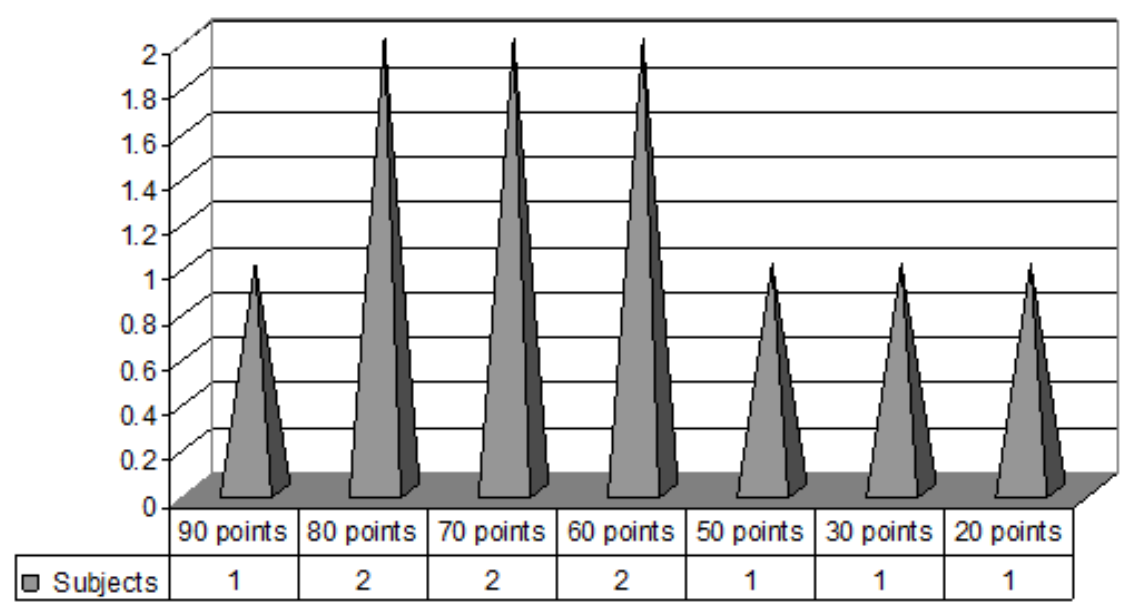

Subjects

Figure 2 Subdivision of subjects according to the number of points obtained in the fixed bar pull-up test

The final performances in the fixed-barpull-up test demonstrate that, in terms of overall upper limb capacity, subjects exhibit, in the vast majority ( 5 subjects, i.e., $50 \%$ ), superior indexes, their performance being of average and good level of those in the evaluation scale, 3 achieved performances ranging from 50 to 60 (Figure 2 ).

The lowest performances were recorded, as in the case of initial testing, by subjects no. 9 and 10 (9 - 2 repeats, respectively, 10. - 3 repeats).

Table 6 Performances and scores recorded by subjects at initial and final testing intrunk lift test

\begin{tabular}{cccll}
\hline Subjects & Initial & Points & Final & Points \\
\hline 1 & 18 repetition & 80 points & 21 repetition & 100 points \\
2 & 21 repetition & 100 points & 22 repetition & 100 points \\
3 & 16 repetition & 60 points & 18 repetition & 80 points \\
4 & 20 repetition & 100 points & 22 repetition & 100 points \\
5 & 15 repetition & 50 points & 18 repetition & 80 points \\
6 & 15 repetition & 50 points & 17 repetition & 70 points \\
7 & 20 repetition & 100 points & 23 repetition & 100 points \\
8 & 17 repetition & 70 points & 19 repetition & 90 points \\
\hline 9 & 5 repetition & 5 points & 9 repetition & 9 points \\
\hline 10 & 13 repetition & 30 points & 15 repetition & 50 points \\
\hline
\end{tabular}

At the end of the comparative analysis of the initial and final performances obtained by the 10 subjects, we present the 5 tests for evaluation of the level of expression of motor skill, as shown in the trunk lift test - Table 6 .The data presented show that from the point of view of expressing the abdominal muscle strength, 8 subjects have increase indices of good and very good level, which represents $80 \%$ 
of their total, obtaining, according to the rating scale, scores between 70 and 100 points; one achieved medium-level performance that brought them a score of 70 and 80 points; two are at the middle of the rating scale with 50 points. Again, we note that subject no. 9 (S.A., 5 initial repeats and 9 final repeats) has the lowest performance, placing him below the lower limit of the rating scale (11 repeats for 10 points), but individual progress is taken into account.

The average performance of the subjects is 18.4 repetitions, which represents a progress of 2.4 repetitions compared to the initial value of the average - 16 repetitions.

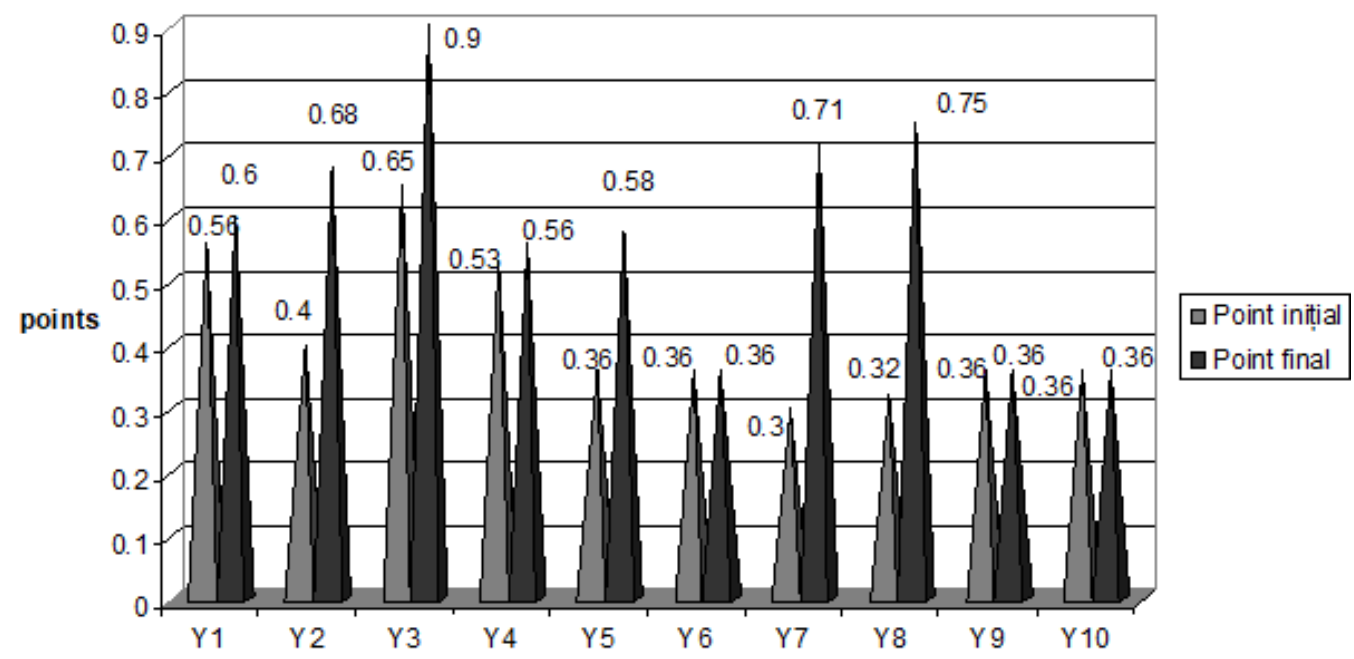

Figure 3 The dynamics of the socio-metric status index of the group of subjects

From the point of view of the values calculated for the socio-metric status index, in the case of the group of subjects, the subjects with the code Y2 is considered the informal leader in the initial testing, while in the final test, the informal leader became the student marked with the code Y3 (Figure 3 ).At the beginning of the study, the configuration of the values calculated for the socio-metric status indicators of the subjects shows a favourable distribution to the lower ones, ranging from 0 to 0.36 , the range of which consists of 5 of the total of 10 , and for only 3 of them did we note an ascending curve whose values are between $0.40-0.65$ (Y4, Y2, Y1, Y3).

The final results highlight the fact that socio-metric index values have become superior to the initial ones, since 9 of the 10 pupils determined, due to the values of the index comprised between 0.36 and 0.9 , a significant level of homogeneity degree. Thus, the final ranking of the 10 subjects after the results obtained is the following: the only one that came close to the value 1 is the subject whose code is Y3 (recorded value Iss $=0.9$ ), considered also the leader of the group; 3 have obtained the value of Iss $=0.36$ (Y6, Y9 and Y10), 4 between 0.45 and 0.68 (Y4, Y5, Y1, Y2) and 2 are very close, 0.71 and 0.75 (Y7, Y8, respectively). The analysis of the data / final results cor- 
responding to the socio-metric status index recorded by the subjects surveyed shows that their group has become more homogeneous. Thus, the Iss values, in this case, the majority of them, 6 , are between $0.45-0.75$, to which the 0.9 is added, while only 3 cases remained around the initially recorded value -0.36 . The group cohesion coefficient at the beginning of the study was equal to 0.09 , and at the end, for the same indicator, the value of 0.44 was recorded, which means the shift from a weak cohesion degree to a medium one Verza and Specială (1993). This indicates an improvement and development of the group relationship, identity, social climate, considered important in the course of school activities, especially for people with special needs, which confirms the working hypotheses.

As far as the 25-meter speed running test is concerned, as a result of initial testing, it is apparent from the initial data that a number of 5 subjects, which represents $50 \%$ of their total, have superior or similar performances to those in the evaluation scale obtaining the maximum score, which demonstrates an increased level of the speed capacity. Only one subject achieved a low performance (9- $6.2 \mathrm{sec}$.), which gave him a score below the $50 \%$ threshold. At the end of the study, we notice a 0.1 - 0.2 sec. improvement of the times recorded for 7 subjects out of 10 , and for two of them a stagnation of performance (subjects 2 and $5-4.6 \mathrm{sec}$, respectively $5.2 \mathrm{sec}$ in both tests), results that led maintaining the initial score (90-100 points) for a number of 6 , an improvement by 5-10 points for subjects 4, 6, 9 and 10. The average performance is $5.02 \mathrm{sec}(0.02 \mathrm{sec}$ above the evaluation scale corresponding to 100 points). The assessment of the lower limb strength level was made based on the results of the standing long jump. From this perspective, $40 \%$ of all subjects achieved the maximum score, $50 \%$ achieved performances that brought them between 75 and 90 points. The lowest score (35 points) was recorded, as in the case of speed running, by subject no. $9(95 \mathrm{~cm})$. Finally, the number of those who scored the highest score increased to 5 (50\%), 4 (40\%) achieved performances that scored between 80 and 95. One alone achieved 50 points with a 15-progress points progress compared to the original one, namely subject no. 9 (from $95 \mathrm{~cm}$ to $110 \mathrm{~cm}$ ). The performances of all subjects improved by $1-10 \mathrm{~cm}$, the mean of the first 5 was $166 \mathrm{~cm}, 6 \mathrm{~cm}$ above the value in the evaluation scale. Although it does not seem a significant evolution, however, these results represent the influence of the exercise programme proposed by us on the 10 subjects, especially if we take into account that the progress of motricity in the case of people with special needs is a slow one, corresponding to a long period of activity. The initial results recorded in the 600 meters resistance test demonstrate that the majority of subjects ( 5 subjects meaning $50 \%$ ) have higher indices of general resistance capacity, their performance being much better than those in the evaluation scale and 4 achieved times between 2.10 minutes and 2.30 minutes. The worst result was recorded, as in the previous tests, by subject no. 9 (3.10 min). The final times (Table 6) show that 9 subjects improved their performance, with a progress between 1-10 seconds. 
The initial performances of two hand overhead throw with medicine ball ( $3 \mathrm{~kg})$, are predominantly below the maximum score that could have been achieved. Thus, only 2 subjects recorded results that brought them maximum score of 100 points. Four of these performances corresponded to the 80-90 points scale and the remaining 3, meaning $30 \%$ of the total score, scored between 40 and 70 points. The average performance of the first two is 5.3 metres $(30 \mathrm{~cm}$ above the score scale of 100 points), 4.7 meters in the case of the next four ( $30 \mathrm{~cm}$ less than the same scale) and for the last three 4.06 meters ( 94 centimetres below the same scale). At the end of the study, $90 \%$ are close to the maximum score that could be achieved. Thus, 5 subjects scored results that brought them the maximum score of 100 points. Three of these performances corresponded to the score of 80-90 points and the remaining 2, meaning $20 \%$ of the total score, scored between 50 and 60 points. The final average value of the performance is 4.88 metres $(12 \mathrm{~cm}$ below value in the evaluation scale corresponding to 100 points), the difference being 24 centimetres ( 0.24 metres), which we consider to be an appreciable progress. Initial results from the fixed-barpull-up test demonstrate that most of the subjects $(60 \%)$ have lower indices of upper limb force capacity, their performance being equal to or below the medium level of those in the evaluation scale, and the remaining 4 got scores between 60 and 70 points. The final performances confirm the improvement of the level of expression of upper limb force capacity in 5 subjects, meaning 50\%, their performance reaching the medium and good level of those in the evaluation scale, 3 achieved performances whose score ranges from 50 and 60 points. As with initial testing, subjects no. 9 and 10 achieved the lowest performances. Initial data obtained in the abdominal muscle strength test demonstrate that 3 subjects have superior indices of this skill, obtaining the maximum score, 4 achieved average performance that brought them between 50 and 80 points, one approaches the lower limit of the rating scale (30 points), and subject no. 9 has the lowest performance, 5 repeats (below the lower limit of the evaluation scale - 11 repeats for 10 points). In the final testing, $80 \%$ of subjects got good and very good performance (from 70 to 100 points), and two are at the middle of the score scale with 50 points. Subject no. 9 remains below the lower limit (9 repetitions in the end), but the individual progress achieved (4 repetitions) is to be taken into account. The average performance of the subjects is 18.4 repetitions, which represents a progress of 2.4 repetitions compared to the initial value of the average - 16 repetitions.

The total number of points achieved by the subjects in the 6 events at initial testing, compared to the final testing (April 2017, Table 7 ), confirm their individual progress. Given the reduced effort availability and morpho-functional deficiencies mentioned above for subjects no. 9 and 10 respectively, it is recommended that they follow their training in accordance with the individual educational plan, in which the contents of physical education and sports activities include: elements of growth and harmonious physical development; exercises for the improvement of the locomotor apparatus; rehabilitation gymnastics under the guidance of the teacher of physical 
education or physical therapy.

At the same time, the final results highlight the fact that the socio-metric index values have become superior as compared to the initial ones, since 9 of the 10 pupils recorded a significant degree of homogeneity due to the values of the index comprised between 0.36 and 0.9 .

The group cohesion index at the beginning of the study had the value of 0.09 , while at the end it was 0.44 , which means the shift from low cohesion degree to a medium one. This indicates an improvement and development of the group relationship, identity, social climate, considered important in the course of school activities, especially for people with special needs, which confirms the working hypothesis.

Table 7 Total score and progress of each subject as a result of passage of control samples initial-final comparative

\begin{tabular}{cccccc}
\hline Subjects & Initial points & Final points & \% max. points & Points difference & \% Increase \\
\hline 1 & 505 & 570 & $95 \%$ & 65 & $12.87 \%$ \\
\hline 2 & 550 & 580 & $96.66 \%$ & 30 & $5.45 \%$ \\
3 & 490 & 530 & $88.33 \%$ & 40 & $8.16 \%$ \\
\hline 4 & 540 & 555 & $92.5 \%$ & 15 & $2.77 \%$ \\
\hline 5 & 421 & 466 & $77.66 \%$ & 45 & $10.68 \%$ \\
\hline 6 & 425 & 470 & $78.33 \%$ & 45 & $10.58 \%$ \\
7 & 570 & 590 & $98.33 \%$ & 20 & $3.5 \%$ \\
\hline 8 & 520 & 550 & $91.66 \%$ & 30 & $5.76 \%$ \\
\hline 9 & 160 & 200 & $33.33 \%$ & 40 & $25 \%$ \\
\hline 10 & 315 & 380 & $63.33 \%$ & 65 & $20.63 \%$ \\
\hline
\end{tabular}

\section{CONCLUSIONS}

We have assumed that pupils with special needs can have proper physical development and motricity to pursue their professional activity and social integration. People with special needs, in our case 15-16 years-old, with mild and medium mental deficiency (Q.I. between 50-70), are educated from a pedagogical point of view. These young people have the opportunity to acquire, during the school period, communication skills, motor skills and aptitudes, social and professional skills suitable for their social integration and self-support. It should be noted that the research we have conductedis in fact an observation research that aimed, on the one hand, to determine the influence of exercise programmes on the recovery and social integration of children with special needs and, on the other hand, to assess the degree of improvement of the motor capacity of children in the same category as a result of exercising C. Pehoiu et al. (2017). Considering the heterogeneity of the subjects surveyed, following the motricity tests, an appreciable progress is notice able with 8 of them, which represents $80 \%$; for the remaining $20 \%$, the progress recorded does not change the status of people with a low level of motor capacity, namely speed, force and strength. The role of physical exercise practice on the social integration 
of pupils with special needs was another objective of this study and of the educational approach we have proposed. And from this point of view, the final results point out that the socio-metric index values have become superior compared to the initial ones, because 9 of the 10 pupils determined, due to the values of the index comprised between 0.36 and 0.9 , a significant level of the homogeneity degree. The cohesion coefficient of the group at the beginning of the study was 0.09 , and at the end the value of 0.44 was recorded, which means the shift from a low degree of cohesion to a medium one. This indicates an improvement and development of the group relationship, identity, and social climate considered important in the course of school activities, especially for people with special needs.

\section{ACKNOWLEDGEMENTS}

There is no conflict of interest. The contribution of the authors to the creation of the article is corresponding to the specified order. The article is part of the research program for 2016-2017, of the specified research department and center. We thank the parents, the school management and the specialized colleague for their involvement in the application of the proposed exercise program, as well as the 26 teachers and physiotherapists who answered the opinion questionnaire.

\section{REFERENCES}

Abid, \& Aslam. (2013). The State Of The World's Children 2013 - Children With Disabilities. In Abid \& Aslam (Eds.), The State Of The World's Children 2013 - Children With Disabilities.

Autism Speaks - Servicii Pentru Familie. Ghidul Comunității Școlare. (2013). Autism Speaks Servicii Pentru Familie. Ghidul Comunităţii Şcolare.

Clerget, S., Adolescenței, E., \& Trei. (2008). Bucureşti.

Debesse, M., Coord, P., \& Copilului. (1970). Editura Didactică Şi Pedagogică.

Dumitru, G. (1997). Sănătatea Prin Sport Pe Înțelesul Fiecăruia. Editura Sportul Pentru Toţi.

Epuran, M., \& Fizice, P. E. (1978). Editura Sport-Turism, Bucure: Ti.

Epuran, M., \& Stănescu, M. (2010). (Învățarea Motrică Aplicații În Activități Corporale, E. Discobolul, \& București, Eds.).

Florea, N. (2008). Procesul Instructiv-Educativ În Şcoala Modernã, Editura Arves. Craiova.

Ghergut, Speciale, A. E. C. C. N., În Cucoș C., Și Grade Didactice, C. P. P. E. D. D., Ii-A, E. A., \& Polirom, E. (Eds.). (2009). București, Pg.

Gherguț, A. (2006). Psihopedagodia Persoanelor Cu Ces. Editura Polirom, Iaşi.

Golu, P., Zlate, M., Verza, E., \& Copilului, E. D. P. (1994). Bucureşti.

Hollowood, T. M., Salisbury, C. L., Rainforth, B., \& Palombaro, M. M. (1994). Use of Instructional Time in Classrooms Serving Students with and without Severe Disabilities. Exceptional Children, 61(3), 242-252. Retrieved from https://dx.doi.org/10.1177/ 001440299506100304 10.1177/001440299506100304

Ilinca, I. . V. (2010). Sportul Adaptat Persoanelor Cu Dizabilităţi.

Jinga, I., Istrate, E., \& Pedagogie, D. (2001). Editura All.

Karstina, S., \& G. (2021). Educators Training In The Context Of Socio-Economic And Technological Trends Of Kazakhstan. Educating Engineers For Future Industrial Revolutions. 
Proceedings Of The 23rd International Conference On Interactive Collaborative Learning (Icl2020), 2, 23-23.

Marcu, V. (1995). Bazele Teoretice Ale Exerciţiului Fizic În Kinetoterapie. Craiova.

Matei, N. C. (1981). Psihologia Relațiilor Morale Interpersonale. Editura Scrisul Românesc, 108-126.

Mellier, D., \& Mouvment. (1993). Grand Dictionnaire Larousse.

Moisin, A. (2007). Arta Educării Copiilor Şi Adolescenţilor În Familie Şi În Şcoală. Edp, Bucureşti.

Momanu, M., Cosma, T., Caracteristici, E., Ipostaze, În Dimensiuni, Cucoș, C., \& Coordonator. (2009). Psihopedagogie Pentru Examenele De Definitivare S,i Grade Didactice (E. A. Ii-A, E. Polirom, \& București, Eds.).

Nicola, I., \& Pedagogie, E. D. P. (1996). Bucureşti.

Pehoiu, În Învățământul Preşcolar, C. C. A. D. E. F., Gimnazial, P. Ş., \& Scaun, E. C. D. (Eds.). (2004). Târgovişte.

Pehoiu, C., Savu, C. F., \& Study. (2017). tudy On The Importance Of Physical Exercise In The Recovery And Social Integration Of Pupils With Special Needs. In On The Importance of Physical Exercise In The Recovery And Social Integration Of Pupils With Special Needs. In: Volume Summaries 4th Central And Eastern European Lumen International Scientific Conference On Education, Sport And Health. 29-30 Septembrie (pp. 166-167). Iași. Iași, România: Lumen Conference Center.

Popescu-Neveanu, P., \& Psihologie, D. D. (1978). Editura Albatros.

Staub, D. (2005). Inclusion And The Other Kids: Here's What Research Shows So Far About Inclusion's Effect On Nondisabled Students. Niusi.

Verza, E. P., \& Specială. (1993). Editura Didactică Şi Pedagogică.

Vrăşmaş, E. ., Coord, Verza, E., Păun, E. Ş., Unicef, Reninco, E., \& Multiprint. (1998). Strategiile Educaţiei Inclusive, În Volumul Educaţia Integrată A Copiilor Cu Handicap. Iaşi.

Vrăşmas, T. (2000). Incluziunea Socială A Copiilor Cu Ces, Editura Vanemonde. Bucuresti. Wallon, H. E., Psihologică, A., \& Copilului. (1978). Editura Didactică Şi Pedagogică. 